\title{
The Metrical Parameters of Word Stress Production and Perception among Iraqi English as a Foreign Language (EFL) Learners
}

\author{
${ }^{*}$ ZAINAB ABBODI ALI ${ }^{1,2}$ \\ ALIAS ABD GHANI ${ }^{1}$ \\ ${ }^{1}$ Translation Department, College of Arts, Tikrit University, Iraq \\ ${ }^{2}$ School of Humanities, Universiti Sains Malaysia, \\ 11800 USM Pulau Pinang, Malaysia \\ *Corresponding author: zainababudiusm@yahoo.com
}

Published online: 30 December 2016

To cite this article: Zainab Abbodi Ali and Alias Abd Ghani. 2016. The metrical parameters of word stress production and perception among Iraqi English as a Foreign Language (EFL) learners. KEMANUSIAAN the Asian Journal of Humanities 23(Supp. 2): 99-117, https://doi.org/ 10.21315/kajh2016.23.s2.6

To link to this article: https://doi.org/10.21315/kajh2016.23.s2.6

\begin{abstract}
This paper disscusses the impact of glocalisation process on the production and perception of Iraqi English as a foreign language (EFL) learners in word stress placement pertaining to metrical parameters. Previous studies lack an in-depth investigation of the parameters tracing the prosodic acquisition path of the learners in acquiring L2 (Archibald 1993; Youssef and Mazurkewich 1998). This study which adopts the metrical parameters model of Dresher and Kaye (1990) shows how similar metrical parameters settings of both Arabic and English affect the performance of Iraqi EFL learners in word stress placement. The findings of the study reveal how Iraqi learners of English internalise the conceptualisation of the metrical parameters of English word stress production and perception in their glocalised variety of English as part of learning the language as an international (global) language. The findings of the study also suggest that Iraqi EFL learners assigned more incorrect responses in word stress placement in the perception task than the production task because they followed different parameter-setting orders in acquiring L2, leading to them resetting more parameters wrongly in the perception task than the production task. The study highlights on the importance of accepting both global and local varieties of English in curriculum development in Iraq.
\end{abstract}

Keywords and phrases: English as an international language, globalisation, glocalisation, word stress production and perception, acquisition of metrical parameters 


\section{Introduction}

According to Crystal (1997), English is one of the most common spoken and taught language across the world since English is regarded as an international language of choice (EIL), or in a more recent phenomena which is known as English as a lingua franca (EIF). This gives English the status as an international or globalised language. Smith (1983) recommends the use of EIL as a teaching method rather than the traditional English as a Foreign Language (EFL) one since learners tend to adopt a localised variety of English when communicating with others. It is a variety which is unique, one that should not be considered as erroneous or deficient. Tsou (2015) states that both EIL and EFL are used interchangeably since the users of English as a foreign or second language (EFL or ESL) have a strong need to use EIL in any way as long as the communicative objective is achieved. Swales (2004) explains that EFL phenomenon has some common foundations with the notion of glocalisation. Sharifian (2013) on the other hand adds that despite the globalisation of English, it has become increasingly localised by many communities of speakers around the world, adopting it to encode and express their cultural conceptualisations. This leads to the development of many varieties of English. This process is commonly referred to as glocalisation of the language (Sharifian 2010). In brief, both EFL and glocalisation have similar conceptions since both of them share the combination of global ideas with local considerations. The English language situation in Iraq is no exception.

Globalisation started in Iraq after the American invasion of Iraq in 2003 as most of the Iraqi learners worked as translators for American troops. At the same time, standard British English is normally used in Iraq universities in which the learners acquire English as taught and produced by British speakers of English. As such, a glocalised variety of English as used by the Iraqi learners of English was already in existence. Alseady (2006) states that Iraqi students have difficulties pronouncing the voicing contrast in the speech sounds of English such as $/ \mathrm{b} / \mathrm{for} / \mathrm{p} /$ like in the word "people" where /bi:bl/ is very often pronounced instead of /pi:pl/. This reflects the interaction that happened between the target language used by Iraqi speakers and the native language used by American and British speakers in/outside the school setting like the interaction that happens in an EIL context. English without doubt has become increasingly important to enable Iraqi learners to communicate with the global world.

This study examines how Iraqi EFL learners produce and perceive English word stress placement using the metrical parameters of Dresher and Kaye (1990) in order to understand how the glocalisation process has influenced the English language and communication among Iraqi learners since the correct stress placement in the word is essential to speak English language correctly. This 
paper in turn will explore the reasons behind the difficulties faced by Iraqi EFL learners when they try to achieve native-like representations for English word stress acquisition.

Stress is one of the most prominent suprasegmental features of language and has an essential role in the processes of comprehension and pronunciation. In articulatory and physiological terms, stress is "the degree of force with which a sound or syllable is uttered" (Jones 1972, 245). Avery and Ehrlich (1992) and Benrabah (1997) contend that word stress represents one of the suprasegmental features that has a major influence on intelligibility. Errors in word stress placement may deter mutual comprehension since it is part of a word's identity. Despite this, little attention has been paid to the acquisition of lexical stress patterns in the L1 and L2 language literature. This is because, on one hand, much research has been conducted on the acquisition of morphological or syntactic rules in contrast to phonological rules. On the other hand, little is known about the acquisition of suprasegmental aspects of phonology in contrast to segmental phonology, particularly consonants (Hochberg 1988).

\section{Theoretical Background}

\section{Previous research}

There are very few studies on the application of the metrical parameters model of Dresher and Kaye (1990) in investigating stress acquisition in L2 learners. The studies of Pater $(1992 ; 1997)$ are among the few early attempts to examine the features of stress acquisition in terms of metrical parameters of Dresher and Kaye (1990). His studies focus on the production of 57 French learners at the word level of three and four syllables of unknown noun words. The main results of these studies reinforce the view that French learners can reset metrical parameters despite the fact that there are differences in the parameters settings between the two languages, i.e., French and English. The study of Archibald (1993) makes an important contribution to examining L2 stress in terms of generative parameters to treat possible stress patterns of the world languages. He investigated the acquisition of the parameters of primary stress production and perception namely, nouns and verbs (disyllabic, trisyllabic and quadrisyllabic) among 23 speakers of Polish, 20 native speakers of Hungarian and 22 native speakers of Spanish. The major findings reveal that the learners can reset the parameters more easily using positive evidence than negative evidence and they have achieved the partial resetting rather than the full resetting of $\mathrm{L} 2$ parameters. In addition, the learners perceived the experimental data better than they produced it. 
Research undertaken by Youssef and Mazurkewich (1998) is of interest since it is the only Arabic study which investigates the stress acquisition of Egyptian learners. It focuses on the metrical parameter resetting in the production and perception of two and three syllables of real words particularly nouns and verbs among 18 native speakers of Cairo Egyptian Arabic (CA) and 16 native speakers of English (control group) from Newfoundland in Canada. The findings show that the learners are able to reset the default values of universal grammar (UG) rather than those of their L1 since all the parameters settings of CA corresponded to the default setting in UG. However, there is no evidence of transferring the parameters values of L1 to L2 and it appears that the learners have performed better in production than in perception.

The researcher opines that such studies are problematic as they do not focus on certain parameters used by learners in sequential order when they follow the prosodic path acquisition suggested by Dresher and Kaye (1990) in resetting the parameters of L2. Such a path is important in helping us understand the reasons behind the learners' difficulties in word stress placement. Therefore, this study will investigate Iraqi learners' word stress production and perception when they follow the prosodic acquisition path in resetting all the parameters of L2 specifically since both languages (Arabic and English) have almost similar setting values.

\section{The metrical parameters of Dresher and Kaye's (1990) model (Metrical tree)}

Dresher and Kaye (1990) suggested a set of universal parameters for constructing metrical structures; these are in the form of labelled trees which express a variety of possibilities in terms of a series of binary parameters. The version of metrical structure adopted here is the metrical foot (metrical parameters) that Dresher and Kaye $(1990,142)$ proposed as a part of Universal Grammar (UG), in particular Chomsky's Government and Binding Theory. The major characteristics of the metrical parameters in the model of Dresher and Kaye (1990) can be summed up as follows:

1. The values of the parameters in language learning are formed according to the acquisition process. The parameters contain default values and the learner must decide which value agrees with the suitable value for the input language otherwise the learner has to move to a different value which is also found also in UG if he/she cannot find the correct value.

2. Each parameter represents every stage of learning path. The parameter remains in its default state till the learner can, when motivated, to move to the marked setting (Meisel 1969). 
3. The cue must be derived from the input and it must be suited to its parameter, i.e., it must reflect the most important features of the parameter (Dresher 1999). In addition, the choice of the appropriate cue for each parameter must be empirically made by the linguist and eventually the process of parameters setting must achieve a partial order set by UG.

\section{The metrical parameters of Arabic and English}

In this study, the properties of stress assignment in both languages (Arabic and English) are determined using the prosodic metrical parameters in the model of Dresher and Kaye (1990) to identify the differences and similarities between L1 and L2. The relevant metrical parameters settings in Arabic (particularly Modern Standard Arabic [MSA]) and English with their default values are shown in Table 1 below:

Table 1. The metrical parameters settings for Arabic and English with their default values

\begin{tabular}{llccc}
\hline & Parameters & Arabic & English & $\begin{array}{c}\text { Dresher and Kaye's } \\
\text { default values }\end{array}$ \\
\hline P2 & Feet are & Binary & Binary & Unbounded \\
P3 & Feet are built from the & Left & Right & Left \\
P4 & Feet are strong on the & Left & Left & Left \\
P5 & Feet are quantity-sensitive & Yes & Yes & No \\
P6 & Feet are quantity-sensitive to the & Rhyme & Rhyme & Rhyme \\
P8A & There is an extrametrical syllable & Yes & Yes & No \\
P8B & There is an extrametrical segment & Yes & Yes & No \\
P8 & It is extrametrical on the & Right & Right & Left \\
\hline
\end{tabular}

We will see how the Arabic stress system of Iraqi learners aligns itself with the English stress system since Arabic and English languages contain somewhat similar values, which are completely different from the default values except for the one parameter determining the word head P4. Figure 1 below shows a sample of the metrical structure of the word venison where the relevant parameters are explained in detail. The word venison is classified into three syllables (HLH) where the first syllable is (ven), the second syllable (i) and the third one (son). The last syllable is regarded as an extrametrical syllable on the right edge of the word (Em-Rt) which means that it is not involved within the metrical foot grouping. The first two syllables are included within the first binary foot and the left most syllable (ven) is stressed which means that the foot headedness is to the left (Ft Hd Lt) and foot direction is to the right (Ft Dr Rt): 


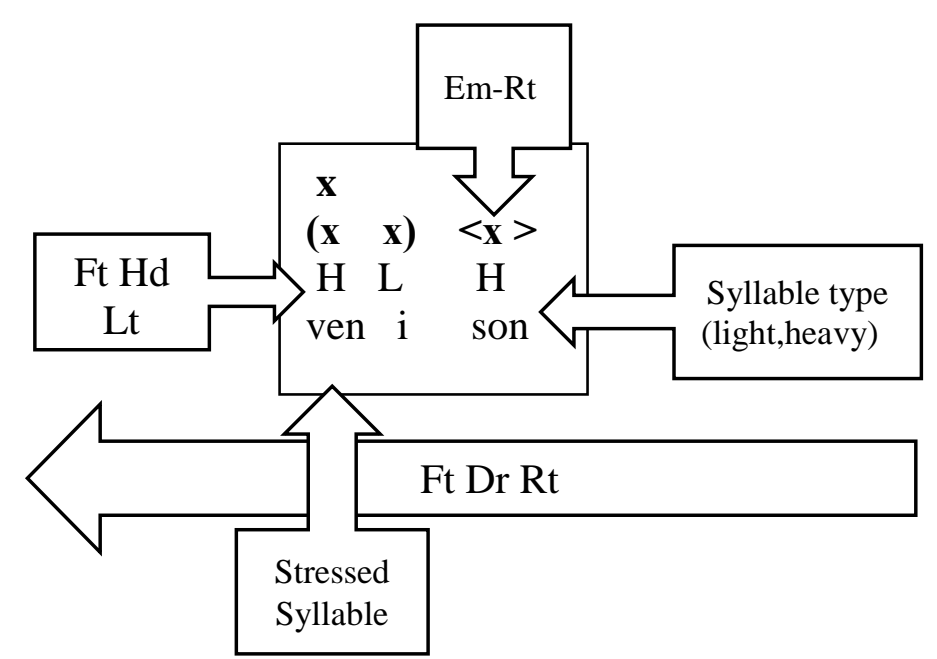

Figure 1. Sample representation of the metrical structure of the word venison

Figure 2 below shows the grid representation of the metrical parameters of stress assignment in Arabic and English language for the Arabic word 'Ca:limun "scientist" and the English word venison respectively:

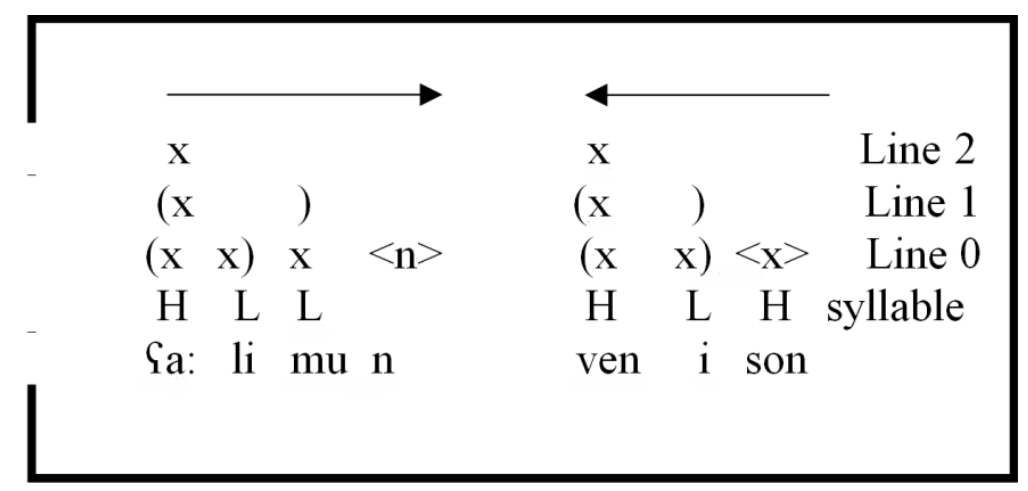

Figure 2. The bracketed-grid structure of metrical parameters of stress assignment in Arabic and English words

The prosodic acquisition path (PAP) of Iraqi learners in resetting the parameters

The process of parameter setting is described as the two languages which are typologically different have certainly different settings while those, which have the same settings for a given parameter, have similar settings (Van der Pas and Zonneveld 2004). In this study, Iraqi learners were guided to follow the path proposed by Dresher and Kaye (1990), step by step starting from the beginning 
until the end, when they are able to set the parameters shown below to their correct values, depending on the positive evidence, in order to acquire L2. The underlined values indicate the correct L2 setting. Figure 3 below shows the prosodic hierarchy of the metrical parameters in English using a tree structure to show how Iraqi learners followed the suggested PAP in the production and perception of word stress placement (the underlined values are the correct ones in each parameter):

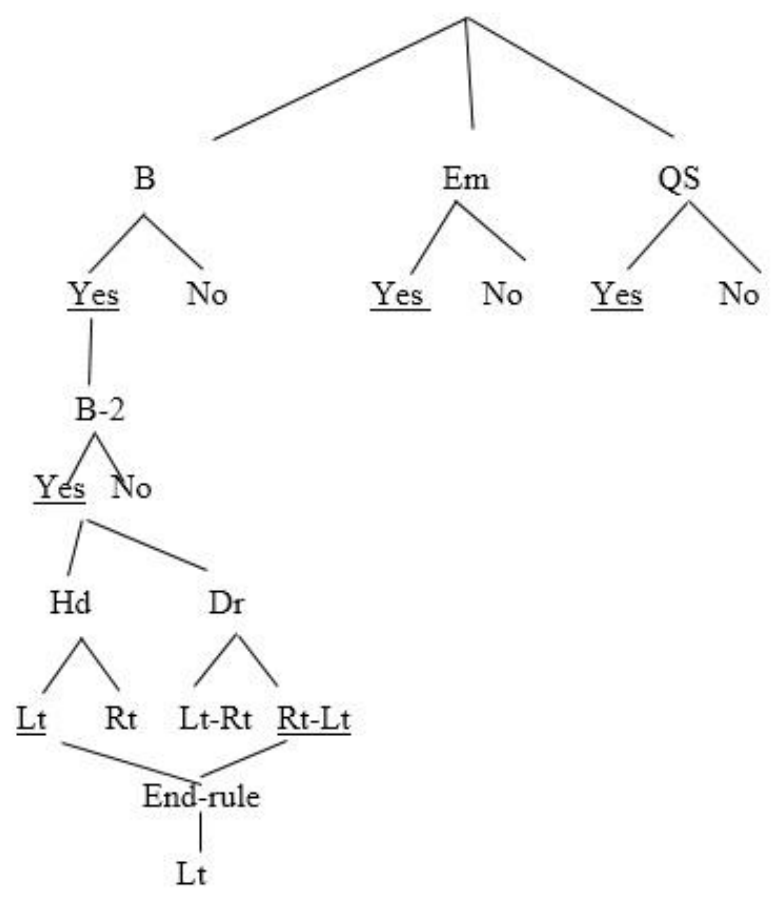

Figure 3. The PAP of Iraqi learners in learning L2

\section{Research Questions}

In order to achieve the objectives, the present study addressed the following two research questions:

1. What are the wrong metrical parameters used by Iraqi EFL learners in resetting the production and perception of common word stress placement?

2. In which task did Iraqi learners use more wrong parameters, causing difficulties in word stress placement? 


\section{Methodology}

\section{Participants}

Fifty Iraqi learners were selected who had studied English as a foreign language for at least ten years and had been living in Baghdad for some time. All of them were educated in MSA and their native language was Arabic. This is why MSA was selected as a basis: to obtain a homogeneous group. The learners' ages ranged from 21 to 28 years. The learners had taken a course in phonetics and phonology and the researcher used the scores of the learners in the second year as a measurement of the learners' ability in spoken English. Only those learners whose scores were 50 and above were selected, to reduce L1 influence on the learners' results (Altmann 2006).

\section{Experimental items}

There are 27 experimental words distributed over seven classes. They were selected according to the following criteria:

1. The words are simple lexical words of bisyllabics and trisyllabics, specifically verbs $(\mathrm{V})$ and nouns $(\mathrm{N})$, not adjectives. Nouns and adjectives have the same rules of word stress placement. Therefore, nouns and verbs were selected because they have different rules of word stress placement that could produce a variation in the results of the data (Roach 2009).

2. The words were selected to reflect a specific aspect of English metrical parameters focusing on stress placement; for example, including the fact that English stress is sensitive to the grammatical category of the item.

3. The words were tested in isolation, using a randomised word list in which the stressed syllable would be clear and in the context of a declarative sentence. The English words appeared in the final position of the sentence preceded by a non-stress bearing lexical item to avoid any possibility of a stress clash or any sort of rhythm phenomenon.

4. The metrical stress patterns of English words represented either a match $(1,3,4,5,6,7)$ or a mismatch (2) of the metrical parameter settings focusing on the stress placement rules for Arabic and English.

\section{Experimental tasks}

In order to investigate Iraqi learners' production and perception in word stress placement, two experimental tasks were conducted with Iraqi EFL learners. This methodology was adapted from Archibald (1993). 


\section{Experiment 1: Production task}

In the first experimental task, the Iraqi learners were examined on their production of word stress in isolation and in a sentence. In the first sub-part, the learners were asked to read a list of randomised words aloud and in the second sub-part, the learners were asked to read a list of sentences which included each of the English words. The focus of the test was not explained to the learners; they were under the impression that their overall pronunciation was being investigated.

\section{Experiment 2: Perception task}

In the second experimental task, Iraqi learners were examined on their perception of word stress in isolation and in a sentence. The perception test was composed of two experimental parts. In the first sub-part, the learners listened to a native speaker pronounce each of the words twice from a laptop computer. The researcher used a natural reader program to ensure that the students heard the words pronounced by a British speaker, since standard British English is normally used in Iraq. All learners underwent a training session to ensure their ability to mark the stress consistently. Once they had performed correctly on three items in a row, the second task would begin. In the second sub-part, the learners listened to the sentence which included the underlined word pronounced by the British speaker and then, s/he marked the stress on the syllable; this was repeated for the sentence-focus task. The learners were given a sheet of paper with written instructions. The learners were asked to assign the stress on the appropriate syllable of the words in isolation, as well as in sentences, on a sheet of paper when they heard the words from the recorder in the computer. Thus, the researcher elicited the learners' stress perception of the items.

\section{Data Analysis}

\section{The metrical parameters of Iraqi learners' common incorrect responses of word stress production and perception}

This study investigates the metrical parameters used by the learners in acquiring L2 when they followed PAP based on the common incorrect responses of learners' word stress production and perception in both tasks. This is carried out to obtain valid results regarding the metrical parameters that are used by learners in relation to their incorrect responses for a particular syllable in each task. In this study, the ultimate stress stands for final syllable, stress on the penultimate (penult) stands for pre-final syllable and stress on the antepenultimate (antepenult) stands for the syllable that precedes pre-final syllable. 


\section{Production of penult stress and perception of ultimate stress in classes 1 and 2}

The learners produced the penult stress wrongly when they reset the values of the parameters Ft Hd to the Rt and Ft Dr from the Lt for the words ending with a heavy syllable. They also applied the Em on the final consonant in the words. They reset the values of $\mathrm{Hd}$ to the Rt and they applied the Em on the final syllable in the words ending with a light syllable. Figure 4 below shows a comparison between the production of a native and non-native speaker (Iraqi) of the word cabinet using a grid structure where a native speaker produced the antepenult stress and the Iraqi speaker produced the penult stress in (a) and (b) respectively:

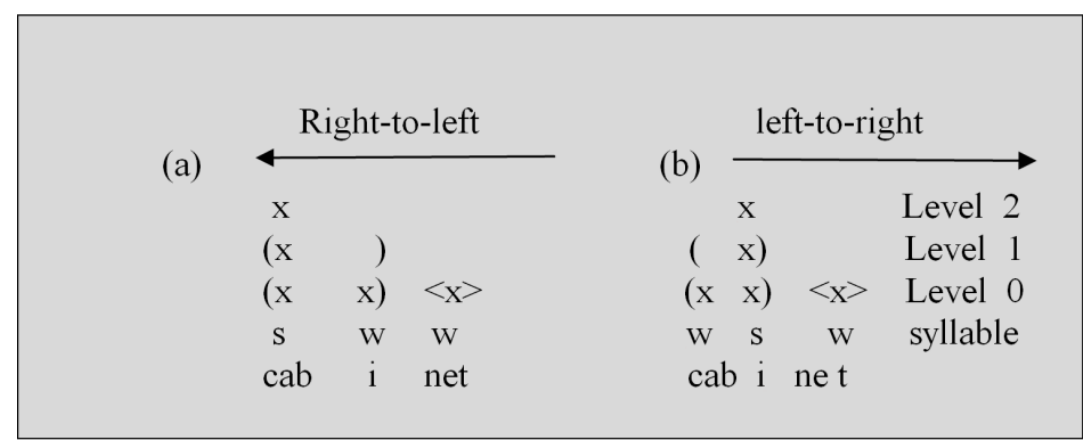

Figure 4. (a) The syllable structure of a native speaker's production of the antepenult stress in the word "cabinet"; (b) The syllable structure of a non-native speaker's production of the penult stress in the word "cabinet"

Figures 5 and 6 below show the PAP of the learners when they produced wrongly the penult stress in words ending with a heavy and light syllable respectively (rectangles are used to include the correct parameters while the ovals include the wrong parameters that the learners had set in their learning L2 throughout the whole study):

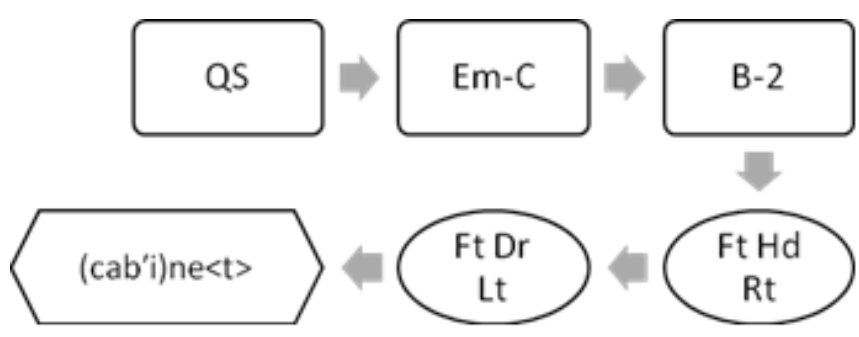

Figure 5. The PAP of learners' penult stress production in words ending with a heavy syllable in classes 1,2 


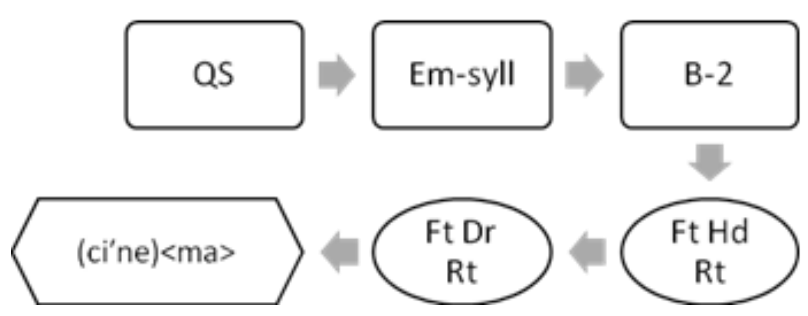

Figure 6. The PAP of learners' penult stress production in words ending with a light syllable in classes 1 and 2

In the perception of the ultimate stress, the learners assigned the ultimate stress wrongly when they wrongly reset the values of Ft $\mathrm{Hd}$ to the Rt and $\mathrm{Dr} \mathrm{Lt}$ for words ending with a heavy syllable and Ft Dr from the Rt for words ending with a light syllable. The learners neglected the Em in both cases. The PAP of the learners when they wrongly perceived the ultimate stress in words with final heavy and light syllables respectively is shown in the following two figures (7 and 8):

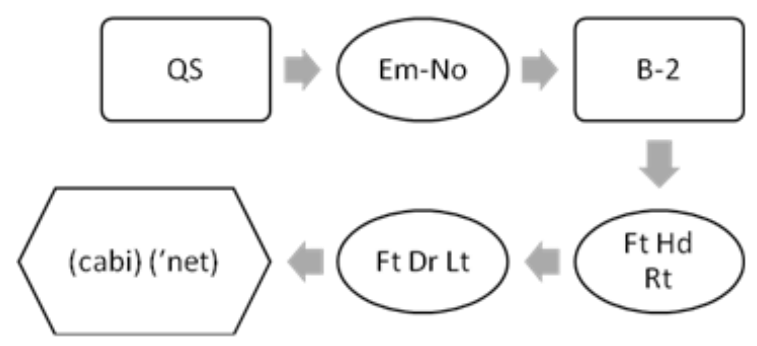

Figure 7. The PAP of learners' ultimate stress perception in words with a final heavy syllable in classes 1 and 2

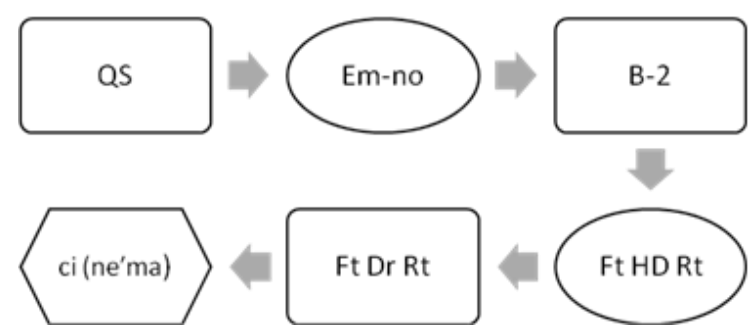

Figure 8. The PAP of learners' ultimate stress perception in words with a final light syllable in classes 1,2

Table 2 shows the values of the metrical parameters settings of Iraqi learners in acquiring L2 when they both produced the penult and perceived the ultimate stress wrongly: 


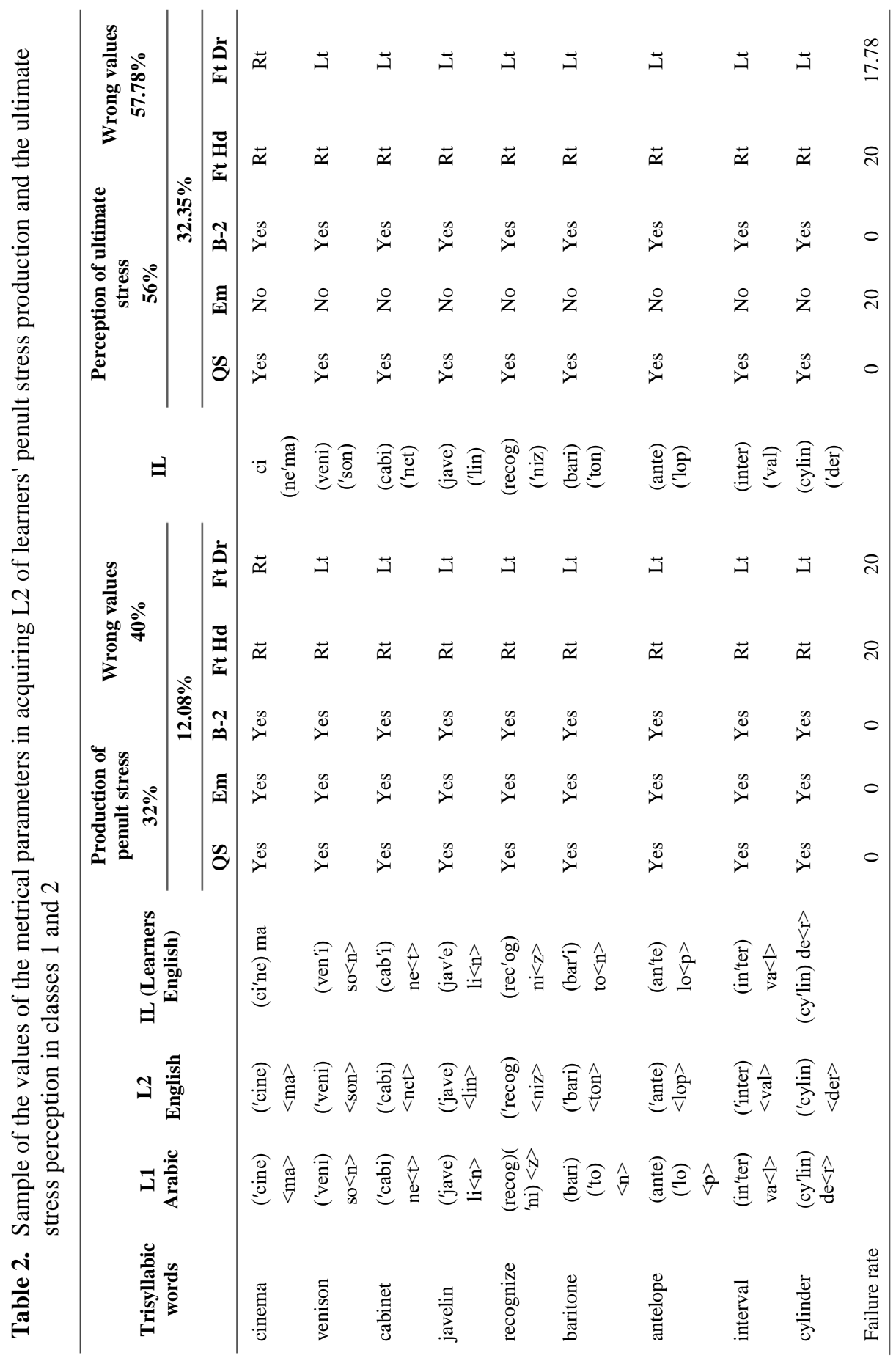


In Table 2 above, the first column represents the English (experimental) words, the second column shows how Iraqi learners should represent these words according to their L1 Arabic, the third column provides the L2 representation of these words in English. Besides, the rest columns provide the learners English (learner's output) and the metrical parameters with their values as Iraqi learners set them when they produced the penult stress and perceived the ultimate stress of the words in this class. Accordingly, the percentages of failure rate of each task are shown at the bottom of each column where the values of metrical parameters for each word are treated equally and given (20) marks for each column. Then, the percentages of failure rate are calculated with the common incorrect responses of each task, i.e., penult stress production and ultimate stress perception.

The results show that the learners reset three correct values of the parameters (QS, B-2, Em) and two wrong values of the parameters $(\mathrm{Hd}, \mathrm{Dr})$ in the production task whereas they reset two correct values of the parameters $(\mathrm{QS}, \mathrm{B}$ 2 ) and three wrong values of the parameters $(\mathrm{Em}, \mathrm{Hd}, \mathrm{Dr})$ in the perception task. The percentages of the failure rate in resetting the values of the parameters in the perception task is (32.35\%) which is higher than in the production task (12.08\%).

\section{Production of antepenult stress and perception of ultimate stress in classes 3, 4} and 5

The learners produced the antepenult stress when they wrongly reset the value of the parameter Ft Dr from the Lt. In addition, the learners applied the Em on the final consonant in the words ending with a heavy syllable and on the final consonant of the words ending with a light syllable.

Regarding the perception of the ultimate syllable, the learners neglected the Em feature at the right edge of the words, as they applied the unmarked value "No" rather than the marked value "Yes". In addition, the learners reset the values of the parameters Hd to the Rt for words ending with a light syllable and Hd Rt with Dr from the Lt for words ending with a heavy syllable.

The learners reset four correct values of the parameters (QS, B-2, Em, Hd) and one wrong value of the parameter (Dr) in the production task, while they reset two correct values of the parameters (QS, B-2) and three wrong values of the parameters $(\mathrm{Em}, \mathrm{Hd}, \mathrm{Dr})$ in the perception task. The percentages of the failure rate in resetting the values of the parameters in the perception task is $(19.43 \%)$ which is higher than in the production task is $(10.22 \%)$. 


\section{Production of penult stress and perception of penult stress in class 6}

The learners applied the Em-Rt on the final syllable of bisyllabic verbs whether these verbs end with a tense or lax vowel. It is important to note that the Em-Rt must be applied on only the final syllable of the verbs that end with a lax vowel rather than a tense vowel since the latter attract the stress on that syllable (Törkenczy 2013). Therefore, the learners reset the value of the parameter Em (no-to-yes) wrongly for words ending with a tense vowel.

However, the learners failed to apply the values correctly, as they reset three values correctly (QS, B-2, Ft Hd) and two values wrongly (Em, Ft Dr) in the production and perception tasks. The failure rate in the production of penult stress is $16.95 \%$ while in the perception of the penult stress is $6.3 \%$. This means that the learners failed in producing the penult stress more than perceiving the penult stress.

\section{Production of penult stress and perception of antepenult stress in class 7}

The learners produced the penult stress wrongly when they reset the values of the parameters Em (yes-to-no) with Dr Lt wrongly for the bisyllabic nouns. In addition, the learners wrongly reset the values of the parameters Em (no-to-yes) with Hd Rt for the trisyllabic nouns.

The learners reset two correct values of the parameters (QS, B-2) and three wrong values of the parameter (Em, Hd, Dr) in the production task, whereas they reset three correct values of the parameters $(\mathrm{QS}, \mathrm{B}-2, \mathrm{Hd})$ and two wrong values of the parameters (Em, Dr) in the perception task. The failure rate in the production of the penult stress is $23.06 \%$ while in the perception of the antepenult stress is $9.33 \%$. This indicates that the learners failed in producing the penult stress more than perceiving the antepenult stress.

\section{Results and Discussion}

The percentages of the common incorrect responses of word stress production and perception in relation to the wrong values of the parameters used by Iraqi learners in acquiring L2 in both tasks for all the classes are summarised in Table 3 below: 
Table 3. The percentages of the learners' common incorrect responses and wrong values of the metrical parameters in both tasks for all the classes

\begin{tabular}{|c|c|c|c|c|}
\hline Class & $\begin{array}{c}\text { Stress } \\
\text { placement }\end{array}$ & $\begin{array}{c}\text { Common incorrect } \\
\text { responses and } \\
\text { parameters values } \\
\text { in the production } \\
\text { task } \\
\%\end{array}$ & $\begin{array}{c}\text { Stress } \\
\text { placement }\end{array}$ & $\begin{array}{c}\text { Common incorrect } \\
\text { responses and } \\
\text { parameters values } \\
\text { in the perception } \\
\text { task } \\
\%\end{array}$ \\
\hline \multirow{3}{*}{$\begin{array}{l}1 \text { (N-antepenult stress) } \\
2 \text { (V \& N-antepenult } \\
\text { stress) }\end{array}$} & \multirow[t]{3}{*}{ penult } & Hd Rt & \multirow[t]{3}{*}{ ultimate } & Em-no \\
\hline & & Dr Lt & & $\begin{array}{l}\text { Hd Rt } \\
\text { Dr Lt }\end{array}$ \\
\hline & & 12.08 & & 32.35 \\
\hline \multirow{4}{*}{$\begin{array}{l}3 \text { (N-penult stress) } \\
4 \text { (N-penult stress) } \\
5 \text { (V-penult stress) }\end{array}$} & \multirow{4}{*}{$\begin{array}{l}\text { ante- } \\
\text { penult }\end{array}$} & Dr Lt & \multirow[t]{4}{*}{ ultimate } & Em-no \\
\hline & & & & Hd Rt \\
\hline & & & & Dr Lt \\
\hline & & 10.22 & & 19.43 \\
\hline \multirow[t]{3}{*}{6 (V-ultimate stress) } & \multirow[t]{3}{*}{ penult } & Em-yes & \multirow[t]{3}{*}{ penult } & Em-yes \\
\hline & & Dr Lt & & Dr Lt \\
\hline & & 16.95 & & 6.3 \\
\hline \multirow[t]{4}{*}{7 (N-ultimate stress) } & \multirow[t]{4}{*}{ penult } & Em-yes & \multirow{4}{*}{$\begin{array}{l}\text { ante- } \\
\text { penult }\end{array}$} & Em-yes \\
\hline & & Hd Rt & & $\operatorname{Dr} \mathrm{Lt}$ \\
\hline & & $\mathrm{Dr} \mathrm{Lt}$ & & \\
\hline & & 23.06 & & 9.33 \\
\hline
\end{tabular}

Notes: $\mathrm{Dr} \mathrm{Lt}=$ left direction; $\mathrm{Hd} \mathrm{Rt}=$ right-headedness; Em-yes = extrametricality is applied on the right edge of the word; Em-no = extrametricality is not applied on the right edge of the word

On one hand, it is clear that the learners failed in resetting the metrical parameters in the perception of the ultimate stress more than the production of the penult and antepenult stress in classes 1,2,3,4,5. This is because the percentages of the ultimate stress in the perception task in classes $(1,2)$ and $(3,4,5)$ are $(32.35 \%)$ and $(19.43 \%)$ respectively. These percentages are higher than the percentages of the penult and antepenult stress in classes $(1,2)$ and $(3,4,5)$ which are $(12.08 \%)$ and $(10.22 \%)$ respectively. On the other hand, the learners failed in resetting the metrical parameters in the production of penult stress more than the perception of the penult and antepenult stress in classes 6 and 7. This is attributed to the point that the percentages of the penult stress in the production task in classes (6) and (7) are (16.95\%) and (23.06\%) respectively. These percentages are higher than the percentages of the penult and antepenult stress in the perception task in classes (6) and (7) which are (6.3\%) and (9.33\%) respectively. 
Generally, scores for the perception task are higher than for the production task which shows that the learners have more difficulties with word stress placement in the perception task than the production task. This is due to the fact that the learners reset more wrong parameters in the perception task than in the production task. This finding is in line with the results of Youssef and Mazurkewich (1998), but it is inconsistent with the results of Archibald (1993); his participants performed better in the perception task than in the production task. The most important factor here is that the sounds of L2 that are different to the L1 are generally acquired easily more than similar ones (Flege 2007). Therefore, the positive settings of both languages can impede the perception of L2 stress while the negative settings of both languages do not have this effect. In this study, the learners had more difficulties in word stress placement in the perception task more than in the production task because of the similar positive parameter settings of Arabic and English which hindered the perception of L2 stress. Table 5 below shows the percentages and the frequency of the wrong metrical parameters used by Iraqi learners in word stress production and perception in all the classes:

Table 4. The percentages and the frequencies of the wrong metrical parameters used by Iraqi learners' production and perception in all the classes

\begin{tabular}{lcccccc}
\hline \multirow{2}{*}{ Wrong metrical parameters } & \multicolumn{2}{c}{ Production } & & \multicolumn{2}{c}{ Perception } \\
\cline { 2 - 3 } \cline { 5 - 6 } \cline { 5 - 6 } & Number & Percentage & & Number & Percentage \\
\hline Dr Lt & 8 & $19.04 \%$ & & 9 & $21.42 \%$ \\
Hd Rt & 3 & $7.14 \%$ & & 9 & $21.42 \%$ \\
Em-yes & 3 & $7.14 \%$ & & 2 & $4.76 \%$ \\
Em-no & 0 & $0 \%$ & & 8 & $19.04 \%$ \\
\hline
\end{tabular}

Notes: $\mathrm{Dr} \mathrm{Lt}=$ left direction; $\mathrm{Hd} \mathrm{Rt}=$ right-headedness; Em-yes = extrametricality is applied on the right edge of the word; Em-no = extrametricality is not applied on the right edge of the word

The results show that the Iraqi learners used the parameter Dr Lt in the perception task more than the production task since its occurrence in the former is $(21.42 \%)$ and in the second task it is (19.04\%). Learners have commonly used this parameter in all the classes for both tasks due to either the influence of L1 or default value. The learners have reset the Dr parameter wrongly in all the classes for both tasks and this may be due to either the influence of L1 or default value. This finding corresponds with the results of Youssef and Mazurkewich (1998), who reported that L2 learners applied the unmarked value of the Dr parameter rather than the marked one but it is difficult to decide whether it was owing to the $\mathrm{L} 1$ or default value since both of them have the same values. The incidence of $\mathrm{Hd}$ $\mathrm{Rt}$ is higher in the perception task than in the production task since the learners used $(21.42 \%)$ in the former and $(7.14 \%)$ in the latter. One important point must 
be mentioned here is that the learners used the marked value (Rt) for the P4 which is not found in both languages (L1 and L2) although it is not the default value since the $\mathrm{Lt}$ value is the value in both languages as well as the default value. Therefore, the learners misset the value which is not found in either their source or target language. In this regard, this finding supports Pater's (1997) finding which shows that his participants used missetting values in their learning L2. The learners used $(7.14 \%)$ of the Em-yes in the production task which is higher than in the perception task $(4.76 \%)$ while they used (Em-no) only in the perception task since its percentage is $(19.04 \%)$. This shows that the learners neglected the Em in the perception task more than in the production task since the learners commonly stressed the final syllable. This is found in most studies such as that of Althman (2006) whose Arabic participants lengthened the final syllable of the words.

\section{Conclusion}

In the light of the previous discussion, the study has concluded the following major findings:

1. The findings reveal strong evidence for the important role of the UG as the Iraqi learners used interlanguage, which is neither L1 nor L2 but is a grammar which is constrained by UG since not all the parameters are transferred. This is evident in the results which showed that the learners can be guided by $\mathrm{L} 2$ parameter values.

2. It is clear that the learners failed in resetting the values of the parameters (Em, Hd, Dr). In particular, the learners ignored the Em only in the perception task while they applied the Em on the final consonant of the words ending with a tense vowel in classes 6 and 7 where there was no Em in either L1 or L2. Therefore, the learners commonly ignored the Em feature in the perception task and transferred their L1 strategy when they stressed the long vowel in the final syllable of the words since they stressed the superheavy syllable in their L1 Arabic. Moreover, the learners were influenced by their L1 when they used the Lt value of the parameter Dr in their Arabic language.

3. Iraqi learners assigned the word stress placement wrongly since the learners followed different parameter-setting orders in learning L2 that caused them to reset more wrong metrical parameters in the perception task than the production task; this may be due to the similar setting values of L1 and L2 which hindered the perception of word stress since they needed to change most of the default values to the L2 values. Further, this study shows that Iraqi learners have misset some values which are neither L1 nor L2. 


\section{Recommendations and Pedagogical Implications}

This study reveals that glocalisation process has an important influence on the performance of Iraqi learners in word stress placement. Practically, teachers in EFL and ESL must focus on the relationship between the EFL teaching and teacher education. In other words, the learners should have already been introduced to this notion in higher education since this is the time when most learners have acquired an adequate understanding of the English language to start using the language in their English and subject classrooms. In this way, the focus will be on both global and local perspectives in curriculum development. Further, a redesigned curriculum in the classroom may include drills that can reduce the influence of glocalised variety of English in performing the word stress placement like the exposure of the learners to multiple voices and localised drills of English (Crystal 1997) which in turn can help Iraqi learners to develop awareness of the mutual influence between Iraqis and various variations of the English language.

Theoretically, this study shows the differences and similarities between Arabic, English language and the learners English. Hence, it is valuable for EFL and ESL teachers, specifically those who teach English in Arabic countries to improve the spoken language of EFL learners of English in particular the stress production: The findings of the study can help them to anticipate the possible problems that Arabic learners of English, particularly Iraqi learners will have when learning English word stress placement since language interference between L1 and L2 is evident in the learner's language. To sum up, the findings of the study offer an interesting insight into how Iraqi learners of English internalise the conceptualisation of the metrical parameters of English word stress production and perception as part of learning English as an International Language.

\section{Bibliography}

Alseady, M. 2006. Shifting from EFL to EIL: History of teaching English for Arabic people. Baghdad: Daralhuria Press.

Altmann, H. 2006. The perception and production of second language stress: A cross linguistic- experimental study. PhD diss., University of Delaware, United States.

Archibald, J. 1993. Language learnability and L2 phonology: The acquisition of metrical parameters. London: Kluwer Academic Publishers, https://doi.org/10.1007/97894-011-2056-2.

Avery, P. and Ehrich, S. 1992. Teaching American English pronunciation. Oxford: Oxford University Press.

Benrabah, M. 1997. Word stress: A source of unintelligibility in English. IRAL 37(3): 157-163, https://doi.org/10.1515/iral.1997.35.3.157.

Crystal, D. 1997. English as a global language. Cambridge: Cambridge University. 
Dresher, B. E. 1999. Charting the learning path: Cues to parameter setting. Linguistic Inquiry 30(1): 27-67, https://doi.org/10.1162/002438999553959.

Dresher, B. E. and Kaye, J. D. 1990. A computational learning model for metrical phonology. Cognition 34(2): 137-195, https://doi.org/10.1016/00100277(90)90042-I.

Flege, I. E. 2007. Acquiring phonology. In The Cambridge handbook of phonology, ed. de Lacy, P., 537-560. Cambridge: Cambridge University Press.

Hochberg, J. 1988. The acquisition of word stress rules in Spanish. PhD diss., Stanford University, United States.

Jones, D. 1972. Outline of English phonetics. Cambridge: W. Heffer and Sons Ltd.

Kirkpatrick, A. 2007. World Englishes: Implications for international communication and English language teaching. Cambridge: Cambridge University Press.

Meisel, J. 1969. Parameters in acquisition. In The handbook of child language, eds. Fletcher, P. and Machwhinney, B., 224-239. New York: John Wiley and Sons.

Pater, J. 1997. Metrical parameter missetting in second language acquisition. In Focus on phonological acquisition, eds. Hannahs, S. J., Pater, J. M. and Young-Scholten, M., 235-261. Amsterdam: John Benjamins.

1992. The acquisition of parameters for word stress by French learners of English. PhD diss., Concordia University, Canada.

Roach, P. 2009. English phonetics and phonology: A practical course. Cambridge: Cambridge University Press.

Sharifian, F. 2013. Globalisation and developing metacultural competence in learning English as an International Language. Multilingual Education 3(7): 1-11, https://doi.org/10.1186/2191-5059-3-7.

. 2010. Glocalization of English in world Englishes: An emerging variety among Persian speakers of English. In Contending with globalisation in world Englishes, eds. Omoniyi, T. and Saxena, M. Clevedon, UK: Multilingual Matters. . 2003. On cultural conceptualisations. Journal of Cognition and Culture 3(3): 187-207, https://doi.org/10.1163/156853703322336625.

Swales, J. 2004. Research genres. Cambridge: Cambridge University Press, https://doi.org/10.1017/CBO9781139524827.

Törkenczy, M. 2013. Word stress. In English phonological analysis, eds. Törkenczy, M., Nádasdy, A., Kiss, Z. G., Szigetvàri, P. and Starčević, A., 1-32. Budapest: Department of English Linguistics, Eötvös Loránd University. Retrieved from http://seas3.elte.hu/phono-analysis/book.html on 7 June 2015.

Tsou, W. 2015. From globalization to glocalization: Rethinking English language teaching in response to the ELF phenomenon. EaGLE Journal 1(1): 47-63.

Van der Pas, B. and Zonnefeld W. 2004. L2 parameter resetting for metrical systems (an assessment and a reinterpretation of some core literature). The Linguistic Review 21(2): 125-170.

Youssef, A. and Mazurkewich, I. 1998. The acquisition of English metrical parameters and syllable structure by adult native speakers of Egyptian Arabic (Cairene dialect). In The generative study of second language acquisition, eds. Flynn, S., Martohardjono, G. and O'Neil, W. A., 303-332. Mahwah, NJ: Lawrence Erlbaum Associates. 